\title{
Predictive factors for the presence of invasive components in patients diagnosed with ductal carcinoma in situ based on preoperative biopsy
}

\author{
Kwan Ho Lee ${ }^{1}$, Jeong Woo Han², Eun Young Kim², Ji Sup Yun², Yong Lai Park ${ }^{2}$ and Chan Heun Park ${ }^{2 *}$
}

\begin{abstract}
Background: In patients diagnosed with ductal carcinoma in situ (DCIS) with needle biopsy before surgery, invasive component (IC) is often found in the postoperative tissue, which results in altered post-surgical care. However, there are no clinically available factors to predict IC, and few MRI studies are available for the detection of IC in DCIS patients. The purpose of this study was to evaluate which risk factors can predict IC preoperatively.

Methods: Patients with a DCIS diagnosis based on preoperative biopsy, who underwent breast surgery Kangbuk Samsung Hospital between Jan 2005 and June 2018, were retrospectively evaluated. Clinico-pathological and breast MRI factors were compared between DCIS and DCIS with IC in postsurgical specimens.

Results: Of the 431 patients with a preoperative diagnosis of DCIS, 34 (7.9\%) showed IC during the postoperative pathological investigations, and 217 (50.3\%) underwent breast MRI. Among MRI-related factors, Mass-like enhancement on MRI was the sole but significant predictor of $\mathrm{IC}(\mathrm{HR}=0.26, \mathrm{C} . \mathrm{I} .=0.07-0.93, p=0.038)$, while nipple-areolar complex invasion, enhancement peak and pattern were not statistically significant. Nuclear grade was the only significant predictor of IC in the analysis of other clinico-pathological factors (HR $=2.39, \mathrm{Cl} . \mathrm{l}=1.05-5.42, p=0.038$ in univariate analysis, $\mathrm{HR}=2.86, \mathrm{Cl} . \mathrm{I}=1.14-7.14, p=0.025$ in multivariate analysis).

Conclusions: Mass-like enhancement on MRI and high nuclear grade were associated with IC in patients with preoperative diagnosis of DCIS. Considering the high sensitivity of breast MRI for IC, further evaluation of the predictive value of MRI in preoperative DCIS patients is desirable.
\end{abstract}

Keywords: Ductal carcinoma in situ, Magnetic resonance imaging, Breast, Biomarkers

\section{Background}

With more than 2 million new cases worldwide in 2018, breast cancer is the most common cancer in women and the second most common cancer overall, according to World Cancer Research Fund International. In ductal carcinoma in situ (DCIS), cancer cells are limited to the duct, as indicated by the term 'in situ' or 'in its original place'. Thus, theoretically, a sentinel lymph node biopsy (SLNB) is not essential for patients with DCIS, which

\footnotetext{
* Correspondence: chanheun1@gmail.com

${ }^{2}$ Department of Surgery, Kangbuk Samsung Hospital, Sungkyunkwan

University School of Medicine, 29 Saemunan-ro, Jongno-gu, Seoul, Seoul 03181, South Korea

Full list of author information is available at the end of the article
}

does not invade adjacent tissues, lymph nodes, and organs beyond the basal cell layer in the mammary duct.

In practice, however, pathological diagnosis using core needle biopsy $(\mathrm{CNB})$ or vacuum-assisted core biopsy (VACB) cannot completely exclude invasive component (IC) before surgery [1-3]. The presence of IC in surgical specimens results in upstaging of DCIS to invasive carcinoma, and changing the post-surgical care plan. It seriously degrades patients' quality of life due to a reoperation for evaluation of axillary lymph node. Especially, when breast reconstruction is performed together, it may result in delayed adjuvant chemotherapy or radiotherapy due to complications of the reconstructed site.

(c) The Author(s). 2019 Open Access This article is distributed under the terms of the Creative Commons Attribution 4.0 International License (http://creativecommons.org/licenses/by/4.0/), which permits unrestricted use, distribution, and reproduction in any medium, provided you give appropriate credit to the original author(s) and the source, provide a link to the Creative Commons license, and indicate if changes were made. The Creative Commons Public Domain Dedication waiver (http://creativecommons.org/publicdomain/zero/1.0/) applies to the data made available in this article, unless otherwise stated. 
Also, Damaging the reconstructed site could be occurred due to radiotherapy or systemic treatment [4].

The purpose of this study was to evaluate which risk factors, including Magnetic resonance imaging (MRI), can predict IC preoperatively in patients diagnosed with DCIS. Previous studies that attempted to determine the risk factors or predictors for preoperative detection of IC yielded discordant results. Until now, only a few small studies evaluated the MRI features as clinical risk factors to predict IC prior to surgery [5-11].

\section{Methods}

\section{Patients}

We retrospectively evaluated the data of 439 patients diagnosed with DCIS based on the pathological analysis of preoperative biopsy specimens of patients who underwent breast surgery at Sungkyunkwan University, Kangbuk Samsung Hospital between Jan 2005 and June 2018. Patients without comprehensive clinico-pathologic data were excluded. Ultimately, 431 patients were eligible for analysis and retrospective review. Clinical information was extracted from medical records including age, imaging findings, biopsy method, tumor grade, pathology results after surgery, treatment information (surgery, radiotherapy, and chemotherapy) and status of estrogen receptor (ER), progesterone receptor (PR), and human epithelial growth factor receptor 2 (HER-2) expression. An MRI study was performed in 217 patients, and MRIrelated factors including tumor size, nipple-areolar complex (NAC) status, enhancement pattern, dynamic curves, and enhancement peak were also gathered. This study was approved by the Institutional Review Board of Kangbuk Samsung Hospital, the Sungkyunkwan University of Korea, on March 3, 2017 (KBSMC 2017-03-018).

\section{Imaging-guided biopsy techniques}

Ultrasonography (US) was performed using a highresolution 5-12 $\mathrm{MHz}$ linear array transducer in CNB. In the examination, patients' breasts were examined in transverse and radial planes with both arms over the head. We obtained bilateral mammograms (medio-lateral oblique and cranio-caudal views) using a standard mammographic unit (Mammomat 3000; Nova Siemens). A specimen detected on US was obtained via US-guided CNB using 16- or 18-gauge needle, and the lesion detected only on mammography was obtained via stereotactic core needle biopsy or excisional biopsy with needle localization. We used an automated gun and a 14-gauge dual-action semiautomatic core biopsy needle with a $22-\mathrm{mm}$-throw.

\section{Magnetic resonance imaging and protocol}

Bilateral breast MRI was performed with a 3.0-Tesla system (Achieva; Philips Medical System, Best, the Netherlands).
Images were obtained with the following protocol: an axial turbo spin-echo T2-weighted(W) imaging sequence with a repetition time [TR]/echo time [TE], 3790/100; matrix size, $332 \times 316$; field of view [FOV], $200 \times 340 \mathrm{~mm}$; section thickness, $3 \mathrm{~mm}$; gap, $1 \mathrm{~mm}$, T1-W with a TR/TE, 620/10; matrix size, $332 \times 332$; FOV, $200 \times 340 \mathrm{~mm}$; section thickness, $3 \mathrm{~mm}$; gap, $1 \mathrm{~mm}$, and dynamic contrast-enhanced examination using a fat-suppressed T1-W 3D fast field echo sequence with a TR/TE, 7.0/3.5; matrix size, 452× 410; FOV, $340 \times 340 \mathrm{~mm}$; section thickness, $2 \mathrm{~mm}$; no gap. For the evaluation of the axilla, delayed axial spin-echo T1W images with a TR/ TE, 532/10; matrix size, $448 \times 378$; FOV, $380 \times 380 \mathrm{~mm}$; section thickness, $5 \mathrm{~mm}$; gap, $2.5 \mathrm{~mm}$ were obtained using a body coil. Dynamic images were acquired before and six times after intravenous injection of $1.0 \mathrm{M}$ gadobutrol (7.5 mL, Gadovist; Bayer Schering Pharma, Berlin, Germany). Image acquisition time per one dynamic scan was 60-120 s. MRI reports were interpreted by two radiologists with 5-15 years' experience in breast imaging (S.H.K., S.H.C) according to the American College of Radiology Breast Imaging Reporting and Data System (BI-RADS) [12]. Lesion size, lesion characteristics (mass or non-mass), lesion morphology (shape, margin, and internal enhancement in mass lesion), and time-signal intensity curve patterns (fast, medium, or slow/persistent, plateau, or washout) were determined.

\section{Pathologic evaluation and immunohistochemical (IHC) analyses}

All patient samples were obtained via image-guided needle biopsy (CNB or VACB) or surgical specimens were fixed in $10 \%$ formaldehyde solution and then embedded in paraffin. A section was stained with hematoxylin and eosin for determination of tumor size, histologic type, nuclear grade, margin status, and presence of metastatic lymph nodes. IHC analysis was performed for the evaluation of ER, PR. HER2 status and ki-67 by an experienced breast histopathologist.

\section{Statistical analyses}

All statistical analyses were performed using the $\mathrm{R}$ version 3.3.2 [13, 14]. Fisher's exact test or the Chi-square test for categorical variables and Student's $t$-test for continuous variables were used to compare the continuous variables between patients with DCIS and those with IC. The Cox proportional hazards regression model was used for univariate and multivariate analyses. All tests were two-sided and $p<0.05$ was considered statistically significant.

\section{Results}

The baseline characteristics of 431 patients are listed in Table 1. These characteristics were compared between patients diagnoses with DCIS and those carrying IC. In 
Table 1 Clinico-pathological features of 431 patients with a preoperative histopathologic diagnosis of DCIS

\begin{tabular}{|c|c|c|c|}
\hline & DCIS $(N=397)$ & Invasive component $(N=34)$ & $p$ \\
\hline Age (yrs) & $50.2 \pm 10.6$ & $50.3 \pm 11.4$ & 0.967 \\
\hline US tumor size $(\mathrm{mm}$, mean $\pm \mathrm{SD})$ & & & 0.663 \\
\hline$\leq 2 \mathrm{~cm}$ & $251(63.2 \%)$ & 19 (55.9\%) & \\
\hline$>2 \mathrm{~cm}$ & $133(33.5 \%)$ & $14(41.2 \%)$ & \\
\hline Not seen & $13(3.3 \%)$ & $1(2.9 \%)$ & \\
\hline US finding & & & 0.567 \\
\hline Non-mass & $42(10.6 \%)$ & $2(5.9 \%)$ & \\
\hline Mass & $355(89.4 \%)$ & $32(94.1 \%)$ & \\
\hline Mammographic finding & & & 0.286 \\
\hline Asymmetry & $25(6.3 \%)$ & $2(5.9 \%)$ & \\
\hline Microcalcification & $292(73.6 \%)$ & $21(61.8 \%)$ & \\
\hline Architecture distorsion & $8(2.0 \%)$ & $2(5.9 \%)$ & \\
\hline No specific finding & $72(18.1 \%)$ & $9(26.5 \%)$ & \\
\hline Biopsy methods & & & 0.001 \\
\hline Needle Biopsy & $250(63.0 \%)$ & $32(94.1 \%)$ & \\
\hline Excisional Biopsy & 147 (37.0\%) & $2(5.9 \%)$ & \\
\hline Surgery type & & & 0.009 \\
\hline Breast conserving surgery & $204(51.4 \%)$ & $9(26.5 \%)$ & \\
\hline Total mastectomy & $193(48.6 \%)$ & $25(73.5 \%)$ & \\
\hline Pathologic DCIS size & & & 0.010 \\
\hline$\leq 2 \mathrm{~cm}$ & $241(60.7 \%)$ & $12(35.3 \%)$ & \\
\hline$>2 \mathrm{~cm}$ & $148(37.3 \%)$ & $20(58.8 \%)$ & \\
\hline No residual DCIS & $8(2.0 \%)$ & $2(5.9 \%)$ & \\
\hline Invasive tumor size ( $\mathrm{mm}$, mean $\pm \mathrm{SD}$ ) & & $7.0 \pm 8.9$ & $<0.001$ \\
\hline $\mathrm{pN}$ & & & 0.117 \\
\hline 0 & $393(99.0 \%)$ & $32(94.1 \%)$ & \\
\hline 1 & $4(1.0 \%)$ & $2(5.9 \%)$ & \\
\hline Multifocality & & & 1.000 \\
\hline Absent & $313(78.8 \%)$ & $27(79.4 \%)$ & \\
\hline Present & $84(21.2 \%)$ & $7(20.6 \%)$ & \\
\hline Nuclear grade & & & 0.125 \\
\hline Low/intermediate & $319(80.4 \%)$ & $23(67.6 \%)$ & \\
\hline High & $78(19.6 \%)$ & $11(32.4 \%)$ & \\
\hline Estrogen receptor & & & 0.177 \\
\hline- & $88(22.2 \%)$ & $12(35.3 \%)$ & \\
\hline+ & $302(76.1 \%)$ & $22(64.7 \%)$ & \\
\hline Unknown & $7(1.8 \%)$ & $0(0 \%)$ & \\
\hline Progesterone receptor & & & 0.130 \\
\hline- & $123(31.0 \%)$ & $16(47.1 \%)$ & \\
\hline+ & $267(7.3 \%)$ & $18(52.9 \%)$ & \\
\hline Unknown & $7(1.8 \%)$ & $0(0 \%)$ & \\
\hline HER2 & & & 0.679 \\
\hline- & $241(61.2 \%)$ & $20(58.8 \%)$ & \\
\hline Overexpression & $147(37.0 \%)$ & $14(41.2 \%)$ & \\
\hline
\end{tabular}


Table 1 Clinico-pathological features of 431 patients with a preoperative histopathologic diagnosis of DCIS (Continued)

\begin{tabular}{|c|c|c|c|}
\hline & $\operatorname{DCIS}(N=397)$ & Invasive component $(N=34)$ & $p$ \\
\hline Unknown & $7(1.8 \%)$ & $0(0 \%)$ & \\
\hline Ki-67(\%) & $8.8 \pm 9.1$ & $15.3 \pm 25.5$ & 0.271 \\
\hline Closest margin (mm) & $4.8 \pm 5.2$ & $5.1 \pm 4.3$ & 0.788 \\
\hline Follow up periods (months) & $46.0 \pm 35.2$ & $61.6 \pm 46.5$ & 0.064 \\
\hline Any recurrence & & & 1.000 \\
\hline Absent & $389(98.0 \%)$ & $33(97.1 \%)$ & \\
\hline Present & $8(2.0 \%)$ & $1(2.9 \%)$ & \\
\hline Chemotherapy & & & $<0.001$ \\
\hline no & $381(96.0 \%)$ & $18(52.9 \%)$ & \\
\hline yes & $16(4.0 \%)$ & $16(47.1 \%)$ & \\
\hline Hormone therapy & & & 0.147 \\
\hline no & $90(22.7 \%)$ & $12(35.3 \%)$ & \\
\hline yes & $307(77.3 \%)$ & $22(64.7 \%)$ & \\
\hline
\end{tabular}

Data are expressed as means \pm standard deviations or $\mathrm{n}(\%)$

Abbreviations: DCIS Ductal carcinoma in situ, US Ultrasonography, HER2 Human epidermal growth factor receptor 2

431 patients in our hospital diagnosed with DCIS before surgery, 397 (92.1\%) were reported having DCIS and 34 patients $(7.9 \%)$ had DCIS with IC based on pathology findings post-surgery. The characteristics were compared between patients diagnoses with DCIS and those with IC. Factors such as biopsy method (needle biopsy or excisional biopsy, $p=0.001$ ), surgery type (breast-conserving surgery or total mastectomy, $p=0.009$ ), pathologic DCIS size $(\leq 2 \mathrm{~cm},>2 \mathrm{~cm}$, or no residual DCIS, $p=0.010)$ varied significantly between the two groups.

MRI scan was performed on 217 of 431 patients and the differences between the two groups are listed in Table 2. Non-mass enhancement (NME) was more common finding in the DCIS group than IC group ( $p=$ $0.002)$. There were no statistically significant differences in MRI tumor size $(\leq 2 \mathrm{~cm},>2 \mathrm{~cm}$, or not seen, $p=$ 0.172), nipple-areolar complex invasion (absent or present, $p=1.000$ ), enlarged lymph node (absent or present, $p=0.612)$, enhancement peak $(\leq 100 \%$ or $>$ $100 \%, p=0.649$ ), initial enhancement pattern of dynamic curve (rapid, medium, or slow, $p=0.735$ ), and kinetic pattern (persistent, plateau, or washout, $p=0.253$ ).

Clinico-pathological predictors of invasive component in patients with preoperative needle biopsy-based diagnosis of DCIS

Among 431 patients diagnosed with DCIS via preoperative biopsy, 149 who were diagnosed with DCIS preoperatively by excisional biopsy, were excluded for this analysis. We investigated the clinico-pathological factors that predicted IC in the surgical specimen obtained during the operation. The results revealed that nuclear grade (hazard ratio $(\mathrm{HR})=2.39$, confidence interval $($ C.I. $)=1.05-5.42, p=0.038$ in univariate analysis, $\mathrm{HR}=$
2.86, C.I. $=1.14-7.14, p=0.025$ in multivariate analysis) was the only significant risk factor for IC in both univariate and multivariate analyses of clinico-pathological predictors (Table 3). Age, US tumor size, US finding, mammographic finding, multifocality, ER, PR, HER-2, $\mathrm{Ki}-67$, and type of operation carried no significant value as predictors of IC.

In MRI-related factors, NME on MRI revealed as a sole significant clinical predictor of DCIS without IC $(\mathrm{HR}=0.26$, C.I. $=0.07-0.93, p=0.038)$. Parameters such as MRI tumor size, nipple-areolar complex invasion, enlarged lymph node, enhancement peak, initial enhancement pattern of dynamic curve, and kinetic pattern were not significant predictors of IC (Table 4).

\section{Discussion}

In our study, we evaluated factors related to upstaging of the diagnosis of breast cancer from pre-operative DCIS to post-operative invasive carcinoma. In previous studies, the risk factors associated with this upstaging such as young age, palpability, nipple discharge, specimen number, extent of microcalcification, mass size, high nuclear grade, axillary lymph node involvement, multicentric lesion, contralateral lesion, and the presence of HER-2 over expression, were reported as predictors of DCIS with IC prior to surgery [1, 4-11, 15-28]. However, these studies were small in sample size and reported inconsistent results, and therefore, no predictable factors for IC were available clinically. In particular, few studies related to MRI, and the number of subjects in these studies was very small. By contrast, the scale of our research is relatively large.

There has been no consensus on age as a predictor for DCIS with IC. Yen et al. found that 55 years of age or 
Table $2 \mathrm{MRI}$ findings of 217 patients with a preoperative histopathologic diagnosis of DCIS

\begin{tabular}{|c|c|c|c|}
\hline & DCIS $(N=202)$ & Invasive component $(N=15)$ & $p$ \\
\hline MRI tumor size & & & 0.172 \\
\hline$\leq 2 \mathrm{~cm}$ & 99 (49.0\%) & $6(40.0 \%)$ & \\
\hline$>2 \mathrm{~cm}$ & $101(50.0 \%)$ & $8(53.3 \%)$ & \\
\hline Not seen & $2(1.0 \%)$ & $1(6.7 \%)$ & \\
\hline Nipple-areolar complex invasion & & & 1.000 \\
\hline Absent & $191(94.6 \%)$ & $14(93.3 \%)$ & \\
\hline Present & $11(5.4 \%)$ & $1(6.7 \%)$ & \\
\hline Enlarged lymph node & & & 0.612 \\
\hline Absent & $166(82.2 \%)$ & $11(73.3 \%)$ & \\
\hline Present & $36(17.8 \%)$ & $4(26.7 \%)$ & \\
\hline MRI NME & & & 0.002 \\
\hline Mass & $102(50.5 \%)$ & $12(80.0 \%)$ & \\
\hline NME & $100(49.5 \%)$ & $3(20.0 \%)$ & \\
\hline Enhancement peak & & & 0.649 \\
\hline$\leq 100 \%$ & $37(18.3 \%)$ & $4(26.7 \%)$ & \\
\hline$>100 \%$ & $165(81.7 \%)$ & $11(73.3 \%)$ & \\
\hline Initial enhancement pattern of dynamic curve & & & 0.735 \\
\hline Rapid & $162(80.2 \%)$ & $11(73.3 \%)$ & \\
\hline Medium & 26 (12.9\%) & $3(20.0 \%)$ & \\
\hline Slow & $14(6.9 \%)$ & $1(6.7 \%)$ & \\
\hline Kinetic pattern & & & 0.253 \\
\hline Persistent & 68 (33.7\%) & 4 (26.7\%) & \\
\hline Plateau & 68 (33.7\%) & $3(20.0 \%)$ & \\
\hline Washout & 66 (32.7\%) & 8 (53.3\%) & \\
\hline
\end{tabular}

Data are expressed as $\mathrm{n}(\%)$

Abbreviations DCIS Ductal carcinoma in situ, US Ultrasonography, NME Non-mass enhancement

younger was the predictor for IC in DCIS [16]. However, Nori et al. suggested that age greater than 55 years at diagnosis was significantly associated with a higher risk of IC [10]. Considering inconsistent results between studies and few studies suggesting age as a significant predictor, age is not likely a predictor, and thus, consistent with our results.

Mixed results suggest nuclear grade as a predictor across the studies. In our analysis, high grade was the only pathological predictor for IC $(\mathrm{HR}=2.39$, C.I. $=$ $1.05-5.42, p=0.038$ in univariate analysis, $\mathrm{HR}=2.86$, C.I. $=1.14-7.14, \quad p=0.025$ in multivariate analysis). Guillot et al. noted that high-grade DCIS was a risk factor of IC [4]. Brennan also reported that highgrade DCIS was significantly associated with a underestimation of DCIS [24]. However, several studies found no relationship between the high grade and the likelihood of upstaging $[1,16,17,19,29]$. This discrepancy is a reflection of the controversy excluding microinvasion from histologic grade; however, this pathological factor is still worthy of investigation in future studies along with other features such as comedo-necrosis.

A larger lesion size in imaging studies has been suggested a predictive factor for upstaging to invasive cancer. In mammography, the cutoff value of size ranged from 20 to $50 \mathrm{~mm}$ in previous studies $[9,27]$. Lee et al. reported that sonographic lesions larger than $20 \mathrm{~mm}$ were significantly related to invasion [30]. Park et al. found that sonographic mass sizes larger than $32 \mathrm{~mm}$ were strong risk factors for DCIS with IC in conjunction with findings suggesting that mass sizes larger than 30 $\mathrm{mm}$ on an MRI were strong predictors for DCIS with IC [9]. Although we evaluated US and MRI tumor size as risk factors for occult invasion, no statistically significant data were obtained with these variables. These varying results might be attributed to insufficient case numbers, use of different cut-off values and diagnostic modalities in each study, and interobserver variability.

The role of MRI in screening and diagnosis of invasive breast cancer is well known [10], but few studies investigated MRI features as preoperative risk factors for occult 
Table 3 Clinico-pathological predictors of invasive component in patients with preoperative needle biopsy-based diagnosis of DCIS

\begin{tabular}{|c|c|c|c|c|}
\hline \multirow[t]{3}{*}{ Variable } & \multicolumn{4}{|c|}{ Risk for invasive component } \\
\hline & \multicolumn{2}{|l|}{ Univariate analysis } & \multicolumn{2}{|c|}{ Multivariate analysis } \\
\hline & $\mathrm{HR}(95 \% \mathrm{Cl})$ & p & $\mathrm{HR}(95 \% \mathrm{Cl})$ & $p$ \\
\hline Age $(>50)$ & $0.75(0.36-1.59)$ & 0.458 & $0.82(0.38-1.79)$ & 0.623 \\
\hline US tumor size (> $2 \mathrm{~cm})$ & $1.31(0.61-2.82)$ & 0.489 & $1.40(0.60-3.26)$ & 0.441 \\
\hline US finding (mass) & $1.52(0.19-12.10)$ & 0.693 & & \\
\hline Mammographic finding (microcalcification) & $0.73(0.34-1.56)$ & 0.416 & $0.83(0.36-1.91)$ & 0.666 \\
\hline Multifocality (present) & $0.95(0.39-2.31)$ & 0.906 & & \\
\hline Nuclear grade (high) & $2.39(1.05-5.42)$ & 0.038 & $2.86(1.14-7.14)$ & 0.025 \\
\hline $\begin{array}{l}\text { Estrogen receptor } \\
\text { (positive) }\end{array}$ & $0.66(0.30-1.45)$ & 0.305 & & \\
\hline $\begin{array}{l}\text { Progesterone receptor } \\
\text { (positive) }\end{array}$ & $0.66(0.31-1.38)$ & 0.266 & & \\
\hline HER-2(overexpression) & $1.05(0.49-2.22)$ & 0.904 & & \\
\hline Ki-67 (> 14\%) & $1.32(0.48-3.62)$ & 0.589 & & \\
\hline $\begin{array}{l}\text { Type of operation } \\
\text { (Mastectomy) }\end{array}$ & $2.25(1.00-5.05)$ & 0.050 & $2.27(0.94-5.50)$ & 0.069 \\
\hline
\end{tabular}

Abbreviations DCIS Ductal carcinoma in situ, US Ultrasonography, HER2 Human epidermal growth factor receptor 2

IC in DCIS patients. Previously, Goto el al. reported that higher signal intensity of the enhancing lesion on fatsuppressed (FS) T2W image was a good predictor of IC [5]. Wisner et al. concluded that rapid early enhancement $(p=0.001)$ and washout kinetics correlated with occult IC in DCIS patients [8]. In contrast to these reports, Park pointed out that a lower signal intensity on FS T2WI MRI, and heterogeneous or rim enhancement on an MRI were significant variables, but not the higher signal intensity of the enhancing lesion on FS T2WI or the time-signal intensity curve pattern [9]. In our analysis, MRI-related variables such as enhancement peak, initial enhancement peak of dynamic curve, and kinetic pattern, showed no significant differences in IC detection. NME was the only predictive factor for DCIS without IC $(\mathrm{HR}=0.26$, C.I. $=0.07-0.93, p=0.038)$.

Based on breast MRI, lesion types were classified into NME or mass. NME on an MRI has been investigated previously as a predictor of DCIS with IC. However, most of them showed no significant correlation between
NME and occult invasion [5-11, 26, 28]. Only two studies suggested that mass-like enhancement was a predictor of DCIS with IC, which is consistent with our study $[11,22]$. It may be explained by previous studies about non-mass lesion (NML) on breast US [31-35]. Most breast malignancies with NML on US were DCIS and only $5.6 \%$ of them were associated with IC alone [35]. Although our results were supported by larger case numbers than in previous studies, the lack of concordance between previous studies and our results suggests the need for re-evaluation of NME on a larger scale and for prospective studies to predict IC.

In kinetic curve assessments, no typical pattern differentiated invasive carcinoma from pure DCIS. Previously, rapid initial enhancement and the washout kinetic curve were reported as predictors of DCIS with IC by Wisner et al. [8]. Another study by Goto el al., showed that kinetic descriptors for initial and delayed phase enhancement had no significant role [5]. A few additional studies also evaluated this enhancement pattern; however, they revealed no

Table 4 Clinical predictors of invasive component on MRI in patients with preoperative diagnosis of DCIS

\begin{tabular}{lll}
\hline Variables & \multicolumn{1}{l}{ Risk for invasive component } \\
\cline { 2 - 3 } & HR (95\% Cl) & $p$ \\
\hline MRI tumor size (> 2 cm) & $1.31(0.44-3.90)$ & 0.632 \\
Nipple-areolar complex invasion (present) & $1.24(0.15-10.31)$ & 0.842 \\
Enlarged lymph node (present) & $1.68(0.51-5.57)$ & 0.399 \\
MRI NME (NME) & $0.26(0.07-0.93)$ & 0.038 \\
Enhancement peak (> 100\%) & $0.62(0.19-2.04)$ & 0.429 \\
Initial enhancement pattern of dynamic curve (rapid) & $1.47(0.45-4.87)$ & 0.526 \\
Kinetic pattern (wash-out) & $2.35(0.82-6.77)$ & 0.112 \\
\hline
\end{tabular}

Abbreviations DCIS Ductal carcinoma in situ, NME Non-mass enhancement 
significant results $[9,11]$. Although no obvious conclusions can be drawn based on MRI enhancement patterns, considering the diagnostic value for breast malignancy, it appears that their significance as a predictor should be elucidated in additional trials in the future.

This study has some limitations. Our study was designed retrospectively, which may lead to bias between the group exposed to MRI scan and the unexposed group. In addition, the difference in tissue volume between CNB and VANB may have affected the diagnostic ability.

\section{Conclusion}

We suggest that high nuclear grade and mass-like enhancement on MRI are predictors of IC in patients with a preoperative diagnosis of DCIS. In clinical practice, no factors are available to predict IC yet. Considering the high sensitivity of breast MRI for an IC, we expect further evaluation of the predictive value of MRI for IC in patients with preoperative DCIS. Therefore, a score system or a calculator that includes clinico-pathological factors and MRI factors is needed to predict DCIS with IC in the future, which can facilitate the treatment plan for patients with DCIS.

\section{Abbreviations}

ADC: Apparent diffusion coefficient; CNB: Core needle biopsy; DCIS: Ductal carcinoma in situ; ER: Estrogen receptor; FS: Fat-suppressed; HER2: Human epidermal growth factor receptor 2; IC: Invasive component; IHC: Immunohistochemical; MRI: Magnetic resonance imaging; NAC: Nippleareolar complex; NME: Non-mass enhancement; NML: Non-mass lesion; PR: Progesterone receptor; SLNB: Sentinel lymph node biopsy;

US: Ultrasonography; VACB: Vacuum-assisted core biopsy

\section{Acknowledgements}

Not applicable.

\section{Authors' contributions}

$J W H, E Y K, Y L P$ and JSY collected and interpreted the patient data, and KHL was a major contributor in writing the manuscript. CHP inspired the topic selection and led the authors. All authors read and approved the final manuscript.

\section{Funding}

None declared.

\section{Availability of data and materials}

The datasets used and/or analyzed during the current study are available from the corresponding author on reasonable request.

\section{Ethics approval and consent to participate}

This study was approved by the Institutional Review Board of Kangbuk Samsung Hospital, the Sungkyunkwan University of Korea, on March 3, 2017 (KBSMC 2017-03-018). The institutional review board waived the need for written informed consent from the participants as the project was deemed to be in the low or negligible risk category in accordance with the Korean National Bioethics Committee 'National Statement on Ethical Conduct in Human Research', 2017.

\section{Consent for publication}

Not applicable.

\section{Competing interests}

The authors declare that they have no competing interests.

\section{Author details}

'Department of Surgery, Eunpyeong St. Mary's Hospital, College of Medicine, The Catholic University of Korea, Seoul, South Korea. ${ }^{2}$ Department of Surgery, Kangbuk Samsung Hospital, Sungkyunkwan University School of Medicine,

29 Saemunan-ro, Jongno-gu, Seoul, Seoul 03181, South Korea.

Received: 8 August 2019 Accepted: 29 November 2019

Published online: 10 December 2019

\section{References}

1. Dillon MF, McDermott EW, Quinn CM, O'Doherty A, O'Higgins N, Hill AD. Predictors of invasive disease in breast cancer when core biopsy demonstrates DCIS only. J Surg Oncol. 2006;93(7):559-63.

2. Maffuz A, Barroso-Bravo S, Najera I, Zarco G, Alvarado-Cabrero I, RodriguezCuevas SA. Tumor size as predictor of microinvasion, invasion, and axillary metastasis in ductal carcinoma in situ. J Exp Clin Cancer Res. 2006;25(2):223-7.

3. Meijnen P, Oldenburg HS, Loo CE, Nieweg OE, Peterse JL, Rutgers EJ. Risk of invasion and axillary lymph node metastasis in ductal carcinoma in situ diagnosed by core-needle biopsy. Br J Surg. 2007:94(8):952-6.

4. Guillot E, Vaysse C, Goetgeluck J, Falcou MC, Couturaud B, Fitoussi A, et al. Extensive pure ductal carcinoma in situ of the breast: identification of predictors of associated infiltrating carcinoma and lymph node metastasis before immediate reconstructive surgery. Breast. 2014;23(2):97-103.

5. Goto M, Yuen S, Akazawa K, Nishida K, Konishi E, Kajihara M, et al. The role of breast MR imaging in pre-operative determination of invasive disease for ductal carcinoma in situ diagnosed by needle biopsy. Eur Radiol. 2012;22(6):1255-64.

6. Deurloo EE, Sriram JD, Teertstra HJ, Loo CE, Wesseling J, Rutgers EJ, et al. MRI of the breast in patients with DCIS to exclude the presence of invasive disease. Eur Radiol. 2012;22(7):1504-11.

7. Mori N, Ota H, Mugikura S, Takasawa C, Tominaga J, Ishida T, et al. Detection of invasive components in cases of breast ductal carcinoma in situ on biopsy by using apparent diffusion coefficient MR parameters. Eur Radiol. 2013;23(10):2705-12.

8. Wisner DJ, Hwang ES, Chang CB, Tso HH, Joe BN, Lessing JN, et al. Features of occult invasion in biopsy-proven DCIS at breast MRI. Breast J. 2013;19(6):650-8.

9. Park AY, Gweon HM, Son EJ, Yoo M, Kim JA, Youk JH. Ductal carcinoma in situ diagnosed at US-guided 14-gauge core-needle biopsy for breast mass: preoperative predictors of invasive breast cancer. Eur J Radiol. 2014;83(4):654-9.

10. Nori J, Meattini I, Giannotti E, Abdulcadir D, Mariscotti G, Calabrese M, et al. Role of preoperative breast MRI in ductal carcinoma in situ for prediction of the presence and assessment of the extent of occult invasive component. Breast J. 2014;20(3):243-8.

11. Lee CW, Wu HK, Lai HW, Wu WP, Chen ST, Chen DR, et al. Preoperative clinicopathologic factors and breast magnetic resonance imaging features can predict ductal carcinoma in situ with invasive components. Eur J Radiol. 2016;85(4):780-9.

12. American College of Radiology. BI-RADS Committee. ACR BI-RADS Atlas: Breast Imaging Reporting and Data System. 5th ed. Reston: American College of Radiology; 2013.

13. Therneau TM, Thomas L. Survival: survival analysis. R package version. 2015; 2:38 https://CRAN.R-project.org/package=survival. Accessed 20 Feb 2018

14. Core Team R. R: a language and environment for statistical computing. Vienna: R Foundation for Statistical Computing; 2016. https://www.R-project. org/. Accessed 20 Feb 2018

15. Wilkie C, White L, Dupont E, Cantor A, Cox CE. An update of sentinel lymph node mapping in patients with ductal carcinoma in situ. Am J Surg. 2005; 190(4):563-6.

16. Yen TW, Hunt KK, Ross MI, Mirza NQ, Babiera GV, Meric-Bernstam F, et al. Predictors of invasive breast cancer in patients with an initial diagnosis of ductal carcinoma in situ: a guide to selective use of sentinel lymph node biopsy in management of ductal carcinoma in situ. J Am Coll Surg. 2005; 200(4):516-26.

17. Goyal A, Douglas-Jones A, Monypenny I, Sweetland H, Stevens G, Mansel RE. Is there a role of sentinel lymph node biopsy in ductal carcinoma in situ?: analysis of 587 cases. Breast Cancer Res Treat. 2006;98(3):311-4.

18. Rutstein LA, Johnson RR, Poller WR, Dabbs D, Groblewski J, Rakitt T, et al. Predictors of residual invasive disease after core needle biopsy diagnosis of ductal carcinoma in situ. Breast J. 2007;13(3):251-7.

19. Lee JM, Kaplan JB, Murray MP, Mazur-Grbec M, Tadic T, Stimac D, et al. Underestimation of DCIS at MRI-guided vacuum-assisted breast biopsy. AJR Am J Roentgenol. 2007;189(2):468-74. 
20. Go EM, Chan SK, Vong JS, Lui PC, Chan AW, Ma TK, et al. Predictors of invasion in needle core biopsies of the breast with ductal carcinoma in situ. Mod Pathol. 2010;23(5):737-42.

21. Chan MY, Lim S. Predictors of invasive breast cancer in ductal carcinoma in situ initially diagnosed by core biopsy. Asian J Surg. 2010;33(2):76-82.

22. Huang YT, Cheung YC, Lo YF, Ueng SH, Kuo WL, Chen SC. MRI findings of cancers preoperatively diagnosed as pure DCIS at core needle biopsy. Acta Radiol. 2011;52(10):1064-8.

23. Han JS, Molberg KH, Sarode V. Predictors of invasion and axillary lymph node metastasis in patients with a core biopsy diagnosis of ductal carcinoma in situ: an analysis of 255 cases. Breast J. 2011;17(3):223-9.

24. Brennan ME, Turner RM, Ciatto S, Marinovich ML, French JR, Macaskill P, et al. Ductal carcinoma in situ at core-needle biopsy: meta-analysis of underestimation and predictors of invasive breast cancer. Radiology. 2011; 260(1):119-28.

25. Kim J, Han W, Lee JW, You JM, Shin HC, Ahn SK, et al. Factors associated with upstaging from ductal carcinoma in situ following core needle biopsy to invasive cancer in subsequent surgical excision. Breast. 2012;21(5):641-5.

26. Hollingsworth AB, Stough RG. Multicentric and contralateral invasive tumors identified with pre-op MRI in patients newly diagnosed with ductal carcinoma in situ of the breast. Breast J. 2012;18(5):420-7.

27. Trentin C, Dominelli V, Maisonneuve P, Menna S, Bazolli B, Luini A, et al. Predictors of invasive breast cancer and lymph node involvement in ductal carcinoma in situ initially diagnosed by vacuum-assisted breast biopsy: experience of 733 cases. Breast. 2012;21(5):635-40.

28. Nadrljanski M, Maksimovic R, Plesinac-Karapandzic V, Nikitovic M, MarkovicVasiljkovic B, Milosevic Z. Positive enhancement integral values in dynamic contrast enhanced magnetic resonance imaging of breast carcinoma: ductal carcinoma in situ vs. invasive ductal carcinoma. Eur J Radiol. 2014;83(8):1363-7.

29. Santamaria G, Velasco M, Farrus B, Zanon G, Fernandez PL. Preoperative MR of pure intraductal breast carcinoma--a valuable adjunct to mammography in assessing cancer extent. Breast. 2008;17(2):186-94.

30. Lee JW, Han W, Ko E, Cho J, Kim EK, Jung SY, et al. Sonographic lesion size of ductal carcinoma in situ as a preoperative predictor for the presence of an invasive focus. J Surg Oncol. 2008:98(1):15-20.

31. Kim SJ, Park YM, Jung HK. Nonmasslike lesions on breast sonography: comparison between benign and malignant lesions. J Ultrasound Med. 2014;33(3):421-30.

32. Ko KH, Hsu HH, Yu JC, Peng YJ, Tung HJ, Chu CM, et al. Non-mass-like breast lesions at ultrasonography: feature analysis and BI-RADS assessment. Eur J Radiol. 2015;84(1):77-85.

33. Lee J, Lee JH, Baik S, Cho E, Kim DW, Kwon HJ, et al. Non-mass lesions on screening breast ultrasound. Med Ultrason. 2016;18(4):446-51.

34. Park JW, Ko KH, Kim EK, Kuzmiak CM, Jung HK. Non-mass breast lesions on ultrasound: final outcomes and predictors of malignancy. Acta Radiol. 2017; 58(9):1054-60

35. Kim HR, Jung HK. Histopathology findings of non-mass cancers on breast ultrasound. Acta Radiol Open. 2018;7(6):2058460118774957.

\section{Publisher's Note}

Springer Nature remains neutral with regard to jurisdictional claims in published maps and institutional affiliations.

Ready to submit your research? Choose BMC and benefit from:
- fast, convenient online submission
- thorough peer review by experienced researchers in your field
- rapid publication on acceptance
- support for research data, including large and complex data types
- gold Open Access which fosters wider collaboration and increased citations
- maximum visibility for your research: over 100M website views per year
At BMC, research is always in progress.
Learn more biomedcentral.com/submissions

